\title{
A MODIFIED APPROACH TO EARTHQUAKE RESISTANT DESIGN OF TORSIONALLY COUPLED BUILDINGS
}

\author{
A.M. Chandler* and G.L. Hutchinson\#
}

\begin{abstract}
SYNOPSIS
All major building codes employ empirical procedures to account for modal coupling between the lateral and torsional responses of a structure. These procedures are implemented using expressions defining an equivalent static design torque. The provisions are based largely on the results of parametric investigations of the earthquake response of simple single-storey building models, which are found to be representative of regular multi-storey structures. This paper presents results obtained by the analysis of the time-history earthquake response of a single storey mono-symmetric building model, leading to the development of an alternative approach for defining the design torque for torsionally coupled buildings. The procedure is based on the concept of effective eccentricity, in which the design lateral displacements of key structural members on the edge of the building are matched to the results of a dynamic analysis. A close approximation to the dynamic responses is derived over the relevant ranges of the important parameters. These parameters include the ratio of torsional to translational natural frequencies, which strongly influences the magnitude of torsional coupling effects in asymmetric buildings.
\end{abstract}

\section{INTRODUCTION}

Buildings with non-coincident centres of mass and resistance respond to earthquakes in coupled vibration modes consisting of both translational and rotational components. Such torsional coupling has been observed in vibrating eccentric structures ${ }^{1}$, and is considered a principal cause of structural fajlure of buildings on earthquake zones ${ }^{2}-4$.

Due to the complex nature of lateraltorsional coupling in earthquake excited buildings, the problem has been considered analytically5-17 in a series of studies employing idealised single-storey building models with either one or two eccentricity components, taken perpendicular to the earthquake direction. Torsionally coupled multi-storey buildings respond, approximately, in a linear combination of the vibration modes of the corresponding uncoupled structure and those of associated single-

Earthquake design codes ${ }^{20-27}$ account for torsional coupling by stipulating that in an analysis of the corresponding uncoupled building (with zero eccentricity between the centres of mass and rigidity for all storeys), the design storey torque

* Lecturer, Department of Civil Engineering, King's College, London.

\# Senior Lecturer, Department of Civil \& Agricultural Engineering, University of Melbourne, Australia.

$$
\mathrm{T}_{\mathrm{b}}=\mathrm{T}_{\mathrm{eb}} \pm \mathrm{T}_{\mathrm{a}}
$$

where $\mathrm{T}_{e b}$ and $\mathrm{T}_{\mathrm{a}}$ are equivalent static torsional moments accounting for static and accidental eccentricity respectively.

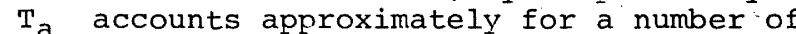
effects which cannot be quantitatively determined, principal amongst these being the influence of rotational ground motion 28 .

Specification of the design storey torque as in eqn. (1) requires that two alternative design cases be considered. As torsional moments produce greatest lateral displacements of structural members nearest the edge of the building, the combined design forces (lateral and torsional) must account for the worst-case situation for members on both sides of the building due to the actual coupled dynamic response components. Hence all building codes specify primary and secondary expressions for design torque, intended principally to account for edge displacements on the flexible and stiff sides of the building, respectively (Fig. 1). CM and CS represent the centres of mass and stiffness in the mono-symmetric building with structural eccentricity $e$, perpendicular to the earthquake direction.

This paper examines the adequacy of the primary torsional design provisions of building codes, together with alternative proposals developed in previous parametric studies, $11,13,16$ in accounting for the neak lateral shear forces in flexible-edge members of a simplified single storey building (location $i$ in Fig. 2) as 


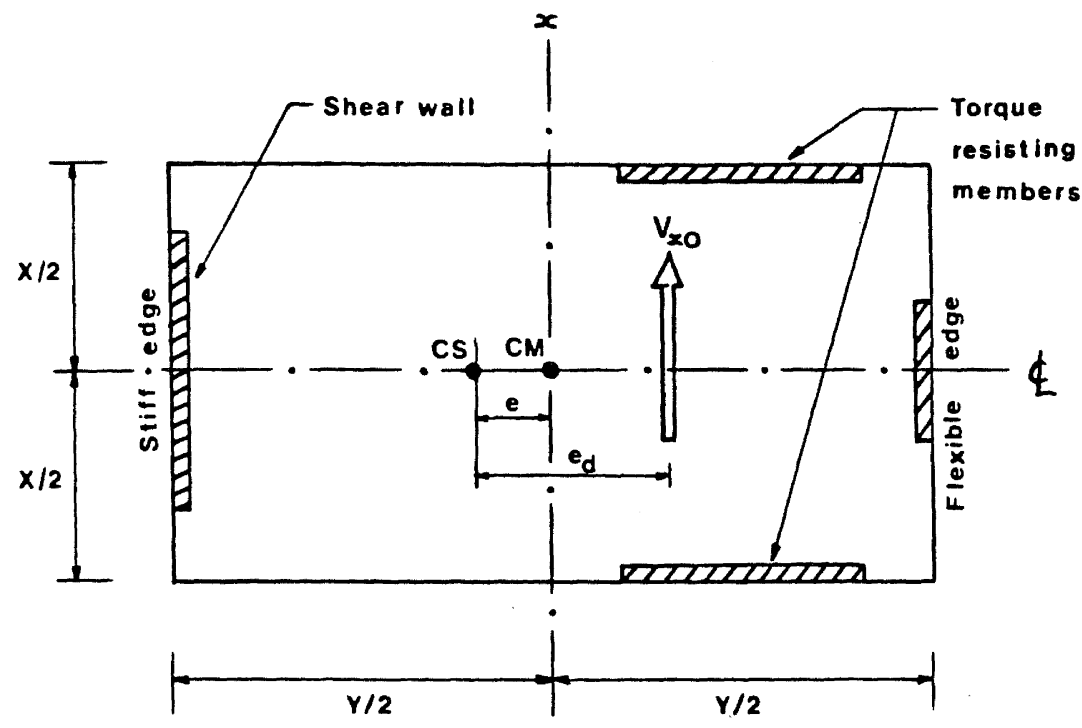

FIG. 1 - PLAN OF SINGLE STOREY MONO-SYMMETRIC STRUCTURAL MODEL
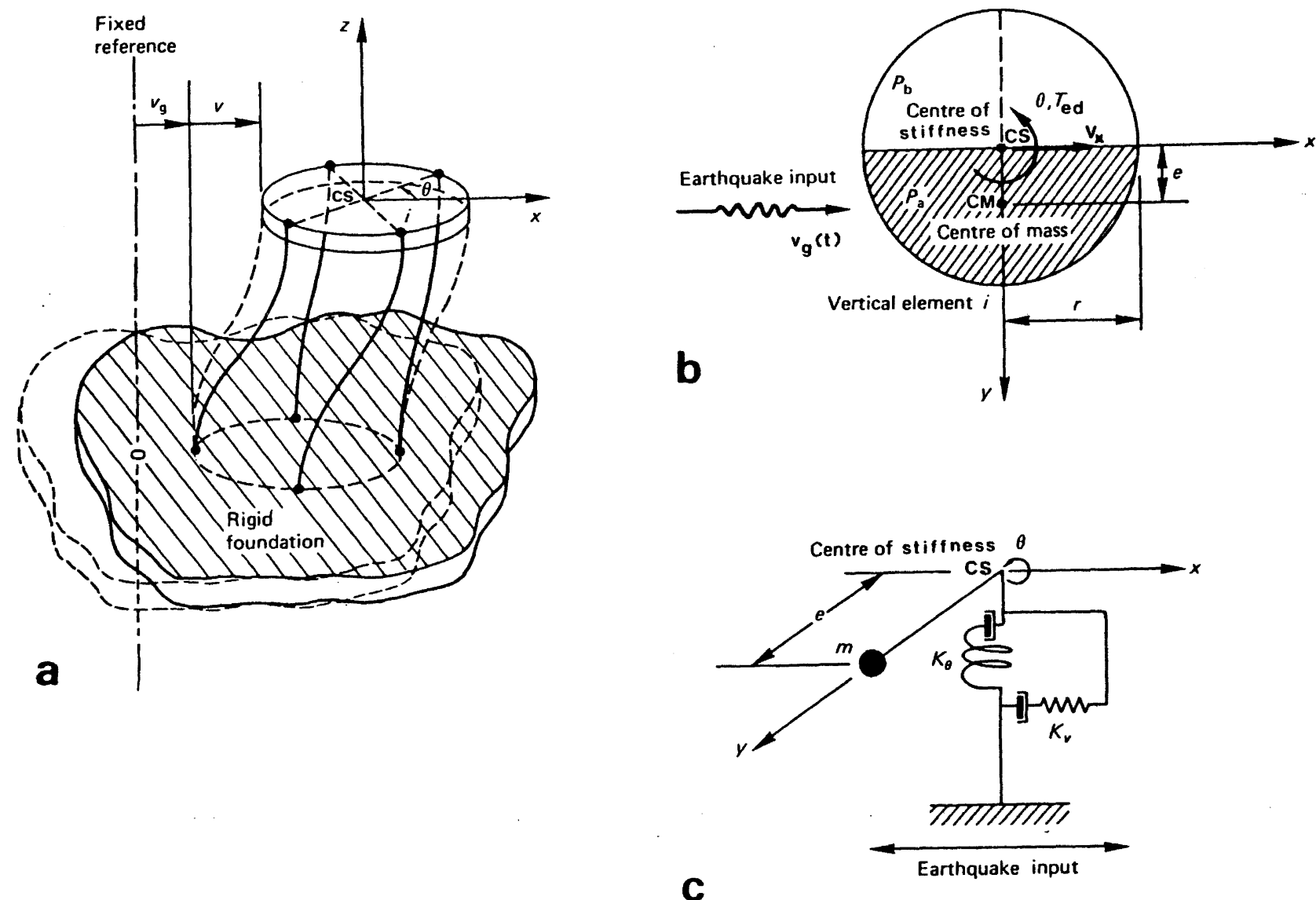

FIG. 2 - TORSIONALLY COUPLED SINGLE STOREY BUILDING MODEL :

(a) RESPONSE UNDER RIGID BASE GROUND EXCITATION ;

(b) TYPICAL PLAN VIEW OF FLOOR DIAPHRAGM ;

(c) CORRESPONDING MATHEMATICAL MODEL. 
computed by time-history dynamic analysis. The study is implemented parametrically and hence the results are applicable to a wide range of actual buildings. In a recent study 15 , the observed response trends were, compared with earlier parametric studies 59 which assumed an idealised earthquake input in the form of spectral acceleration design curves.

Since the combined shear force acting on individual members due to both lateral and torsional response effects is of fundamental interest in design, the design torque should logically be derived by consideration of the dynamic edge displacement. In contrast, the design provisions of existing building codes are based on equating the design and dynamic torques, and as such have been shown ${ }^{9}$ to provide generally poor agreement with the peak edge displacements (or member shears) derived from dynamic analysis. The recommendation of Dempsey and Tsoll, that modal coupling effects be accounted for in design by specifying effective torsional moments which match the dynamic lateral edge displacement has been adopted in this study. The timehistory approach is used to develop an approximate relationship between the effective and static eccentricies required to account for peak coupling effects. Further, recommendations are made which allow the designer the option of reducing the effective torsional moment in cases where the influence of torsional coupling is less significant. In particular, the ratio of uncoupled torsional to translational natural frequencies is shown to be very influential in determining the extent of lateral-torsional coupling. Its effect is accounted for numerically by the adoption of a modification factor $(<1.0)$ to enable safe reduction of the non-accidental component of the torsional design moment.

\section{DYNAMIC ANALYSIS}

The structural system analysed consists of an eccentric mass single-storey building with a symmetrical distribution of structural elements providing both lateral and torsional resistance. Hence the centre of stiffness, CS, coincides with the centre of the floor slab, which is assumed to consist of a rigid circular diaphragm (Fig. 2) of radius, $r$, and mass, $m$. The centre of mass, CM, is offset by a distance $e$, perpendicular to the direction of earthquake excitation $v_{g}(t)$. The static eccentricity e arises because of differing mass densities $\mathrm{p}_{a}, \mathrm{p}_{\mathrm{b}}$ $\left(\mathrm{p}_{\mathrm{a}}>\mathrm{p}_{\mathrm{b}}\right)$ in the two halves of the floor disc and is therefore limited to the range 12 $0<e<4 r / 3 \pi(0.42 r)$. The model shown in Fig. 2 has two degrees of freedom defined by the translation $v(t)$ and rotation $\theta(t)$ at the centre of stiffness CS. When subjected to uni-directional, rigid-base earthquake excitation at right angles to the axis of symmetry (i.e. in the $x-$ direction), the building responds in two coupled modes of vibration, including both the lateral and torsional response components. The particular floor shape has been chosen since its facilitates the extension of the present study to include the ${ }^{2}, 1$ fects of soil-structure interaction

\section{Equation of motion}

The parametric form of the undamped equation of motion is writtenl4

$\left[\begin{array}{cc}1 & e_{r} \\ e_{r} & 0.5\end{array}\right]\left(\begin{array}{c}\ddot{v}^{\prime}+\ddot{v}_{g} \\ \ddot{v}_{\theta}\end{array}\right)+\omega_{v}^{2}\left[\begin{array}{cc}1 & 0 \\ 0 & 0.5 R_{f}^{2}\end{array}\right]\left(\begin{array}{l}v \\ v_{\theta}\end{array}\right)=\left(\begin{array}{l}0 \\ 0\end{array}\right)$

where the system is characterised by its uncoupled translational natural frequency, $\omega$, and the dimensionless quantities e $\left(\underline{\underline{v}}^{\prime} \mathrm{e} / \mathrm{r}\right)$ and $R_{f}$. The parameter $R_{f}$ is rellated to the ratio of torsional to translational stiffnessl2 such that $R_{f}^{2}=\left(2 / \mathrm{r}^{2}\right)\left(\mathrm{K}_{\theta} / \mathrm{K}_{\mathrm{V}}\right)$. The term $v_{\theta}=r \theta$ represents the displacement at the edge of the disc (point $i$ in Fig. 2) due to the torsional component of response.

Putting $\ddot{v}_{g}=0$ in equation (2) yields the free-vibration equation and leads to the following expressions for frequencies $\omega_{1}$ and $\omega_{2}\left(\omega_{1}<\omega_{2}\right)$ of the coupled system:

$\Omega_{\mathrm{n}}^{2}=\omega_{\mathrm{n}}^{2} / \omega_{\mathrm{v}}^{2}=\frac{-\mathrm{B} \pm \sqrt{\left(\mathrm{B}^{2}-4 \mathrm{AC}\right)}}{2 \mathrm{~A}} ; \mathrm{n}=1,2$

where $A=0.5-e_{r}^{2}$

$$
\begin{aligned}
& B=-0.5\left(I+R_{f}^{2}\right) \\
& C=0.5 R_{f}^{2}
\end{aligned}
$$

The variation of $\Omega_{n}(n=1,2)$ with $R_{f}$ and $e_{r}$ has been presented and discussed in Reference 14 .

For harmonic ground displacement $v_{g}=\bar{v}_{g} \exp (i \omega t)$, the steady-state responses at frequency $\omega$ are expressed in terms of complex frequency response functions $\mathrm{H}_{\mathrm{V}}$, $\mathrm{H}_{\theta}$ where for the linear system under consideration $\mathrm{v}=\mathrm{H}_{\mathrm{v}} \exp (i \omega t)$ and $\mathrm{v}_{\theta}=\mathrm{H}_{\theta}$ $\exp (i \omega t)$. Assuming the building has normal modes with equal viscous damping $\xi$ expressed as a ratio of critical damping, solution of the equations of motion yields 14

$$
\begin{array}{r}
{\left[\begin{array}{cc}
\left(1 / \Omega_{1}^{2}-f^{2}+2 i \xi f D_{v v}\right) & e_{r}\left(-f^{2}+2 i \xi f D_{v \theta}\right) \\
e_{r}\left(-f^{2}+2 i \xi f D_{v \theta}\right) & \left(0.5 R_{f}^{2} / \Omega_{1}^{2}-0.5 f^{2}+i \xi f D_{\theta \theta}\right)
\end{array}\right]} \\
\left(\begin{array}{l}
\mathrm{H}_{v} / \bar{v}_{g} \\
\mathrm{H}_{\theta} / \bar{v}_{g}
\end{array}\right)=f^{2}\left(\begin{array}{c}
1 \\
e_{r}
\end{array}\right)
\end{array}
$$

where $D_{y y}, D_{y}$ and $D_{\theta \theta}$ are dimensionless damping 'Co'ffYcients for the structurel2 and $f$ is the normalised harmonic excitation frequency $\omega / \omega_{1}$.

\section{Time history earthquake response}

A series of seven historical strong motion European earthquake records with peak ground accelerations ranging between 
0.20 and $0.6 \mathrm{lg}$ have been used to evaluate the time-history response of the torsionally coupled building model. These consist of the Romanian (1977), Leukas, Greece (1973), Thessaloniki, Greece (1978), and Patras, Greece (1974) earthquakes, together with three separate recordings from the AnconaRocca (Italy) earthquake (1972). The El Centro, California (1940) record has also been included for comparison with the European records. References 12 and 14 contain a detailed assessment and discussion of the spectral properties of these earthquake records including complete sets of corrected acceleration time-histories and their response spectra, as well as integrated ground velocity and displacement records.

Transient displacement responses have been computed using a frequency domain technique 29 ; the response functions $\mathrm{H}_{\mathrm{v}}, \mathrm{H}_{\theta}$ are computed from eqn. (5) at discrete frequency intervals $\Delta f=\Delta \omega / \omega]$. The structural system is parameterised by $e_{r}$, $\mathrm{R}_{\mathrm{f}}$ and $\xi$. The natural frequencies $\omega^{l}$, $\omega_{2}$ depend additionally on the uncoupled translational natural period $\mathrm{T}_{\mathrm{V}}\left(=2 \pi / \omega_{n}\right)$ taken over the range 0.1 to $2.0 \mathrm{sec}$ in order to minimise the effect of random fluctuations in the frequency content of the individual earthquake records. The results presented correspond to the mean, mean +1 standard deviation $(\sigma)$, and extreme responses, a process which is justified in parametric studies provided a sufficient number of records and structural periods are considered.

The combined effect $v_{i}(t)$ of the translational and torsional response components, $v(t)$ and $v_{\theta}(t)$, on the lateral displacement of a typical edge member $i$ (Fig. 2) has been calculated. This quantity is of direct importance in an evaluation of the provisions of the building codes, and in developing a modified approach to design based on effective as opposed to dynamic torsional moments. Since maximum response effects are of prime importance in design, the results presented in this study are based on peak values of the response $v_{i}(t)$, henceforth designated $v_{i}^{\max }$.

\section{EFFECTIVE ECCENTRICITY APPROACH}

The effective eccentricity e el designates the primary torsional design requirement, found by matching the peak edge displacement (and hence the design lateral force) of vertical element $i$ obtained by dynamic analysis, with the corresponding displacement obtained using an effective storey torque given by

$$
\mathrm{T}_{\mathrm{ebl}}=\mathrm{e}_{\mathrm{el}} \mathrm{V}_{\mathrm{xO}}=\mathrm{e}_{\mathrm{elr}}\left(\mathrm{r} \mathrm{V}_{\mathrm{xO}}\right)
$$

where $\mathrm{V}_{\mathrm{x}}$ represents the design storey shear as specified by all the building codes considered in this study, determined by analysis of the response of the uncoupled (single degree of freedom) structure to specified earthquake loading. Hence

$$
v_{x o}=k_{v} s_{d}\left(\omega_{v}, \xi\right)
$$
where $\mathrm{S}_{\mathrm{d}}$ is the spectral (peak) displace-
ment.
The lateral force acting on the vertical structural element $i$, based on the design torque and shear given in eqns. (6) and (7) respectively, is given by

$$
F_{\text {vib }}=\left[\frac{\mathrm{v}_{\mathrm{xo}}}{\mathrm{K}_{\mathrm{v}}}+\frac{\mathrm{T}_{\mathrm{ebl}}{ }^{\mathrm{r}}}{\mathrm{K}_{\theta}}\right] \mathrm{k}_{\mathrm{vi}}
$$

where $k_{v i}$ is the lateral stiffness of member i.

Hence

$$
F_{v i b}=S_{d}\left(\omega_{v}, \xi\right)\left[1+\frac{2 e_{e l r}}{R_{f}^{2}}\right] k_{v i}
$$

The maximum lateral force on element $i$ arising from dynamic analysis is given by

$$
\mathrm{F}_{\mathrm{vi}}=\mathrm{v}_{i}^{\max } \mathrm{k}_{\mathrm{vi}}
$$

and hence equating $F_{v i b}$ and $F_{v i}$ using eqns. (9) and (10) yields

$$
R_{i}=\frac{v_{i}^{\max }}{s_{d}\left(\omega_{v}, \xi\right)}=1+\frac{2 e_{e l r}}{R_{f}^{2}}
$$

The design effective eccentricity ratio is therefore

$$
e_{e l r}=\frac{R_{f}^{2}}{2}\left(R_{i}-1\right)
$$

For buildings with small structural eccentricity $e_{r}$ (Fig. 3(a)), and for $R_{f}<$ 0.8 , the effective eccentricity eelr is negligible. Within this range, therefore, the effective torsional moment (eqn. (6)) can be neglected. Hence the edge displacement is adequately matched by the application of the design storey shear $v_{x o}$ alone, acting at CS. It should be noted that most real buildings have values of $R_{f}$ in the range $0.6<R_{f}<2.0$, hence the value of $R_{f}$ at which peak response occurs is important in formulating appropriate design recommendations. The results presented in Fig. 3 indicate that maximum response occurs for $R_{f}$ in the range $1.0-1.4$, hence the conclusion of studies based on evaluation of dynamic eccentricity $e_{d} 8,9$ (defined as the distance from CS at which the design shear $v_{x o}$ must be placed in order to produce the dynamic torque $\mathrm{T}_{\text {ed, }}$, see $\mathrm{Fig}$. 1) that maximum modal coupling effects are exhibited for $R_{f} \simeq 1.0$ is not necessarily valid for consideration of dynamic edge displacement. Response to the El Centro record (shown dashed in Fig. 3) generally exceeds the 'mean $+1.0 \sigma^{\prime}$ European response curve for $R_{f}>1.0$, but tends to the mean European response for small values of $R_{f}$.

Fig. 4 compares the 'mean +1.00 ' European responses with the recently proposed design expressions given by Pekau and Rutenberg in Reference 16, which were derived from a similar study based on the response to five Californian earthquakes (including the NS $1940 \mathrm{El}$ Centro record). The proposed eccentricity to be employed for members on the flexible side of CS is given by Pekau and Rutenberg as 

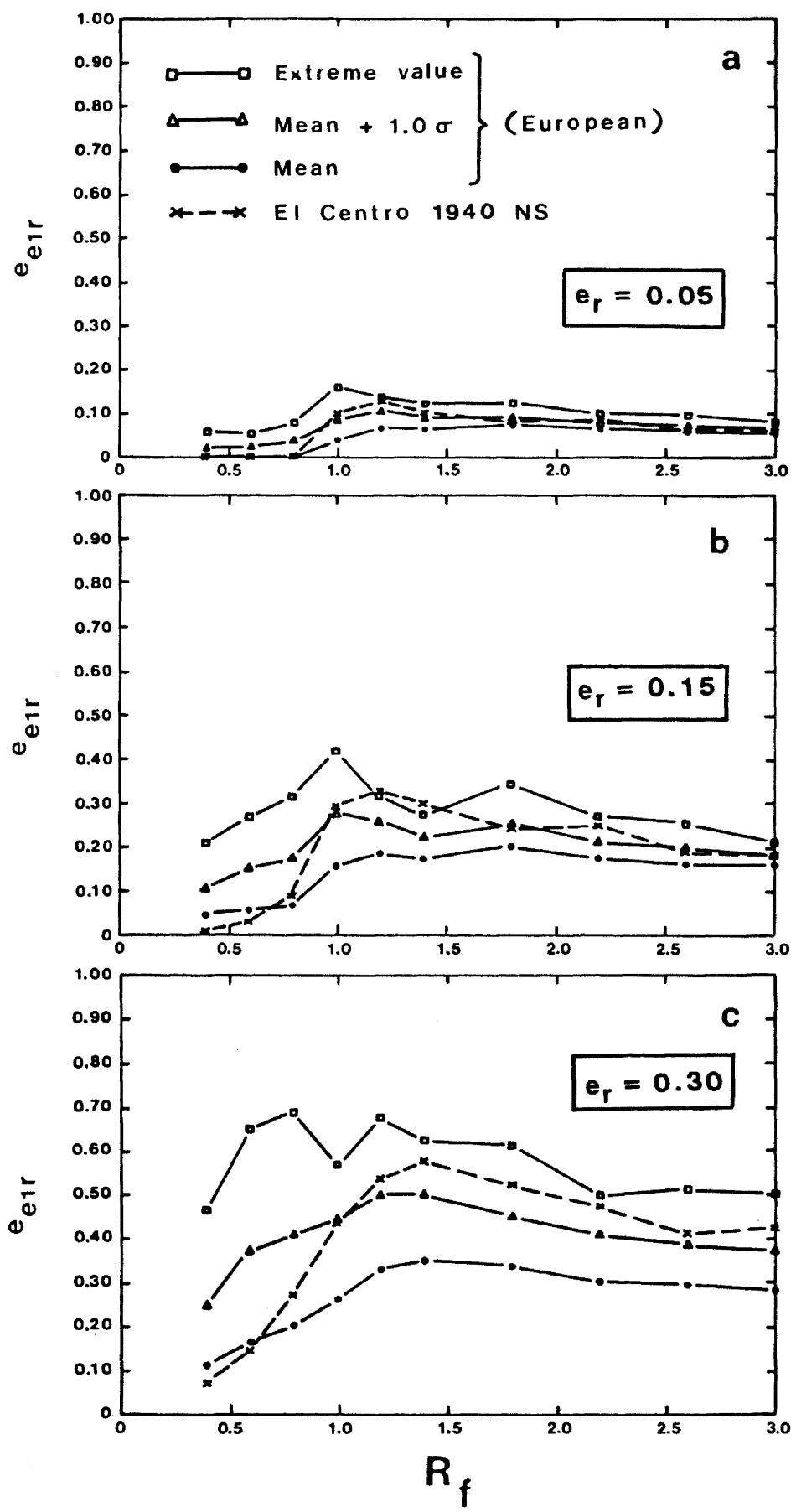

FIG. 3 - VARIATION OF THE PRIMARY EFFECTIVE ECCENTRICITY RATIO WITH $R_{f}$, BASED ON RESPONSE TO SEVEN STRONG-MOTION EUROPEÂN EARTHQUAKE RECORDS

$$
e_{e l}=\left[\frac{2.5 \rho\left(\Omega_{0}\right)^{1 / 2}}{\rho+e}\right] e
$$

where $\rho$ is the mass radius of gyration about $\mathrm{CM}$, and $\Omega_{0}$ is defined as the ratio of the stiffness radius of gyration about $\mathrm{CS}$, to $\rho$. Hence for the model shown in Fig. 2

$$
\Omega_{0}=\left(K_{\theta} / \rho^{2} k_{v}\right)^{1 / 2}
$$

and

$$
\rho^{2}=\tau^{2}-e^{2}=r^{2} / 2-e^{2}
$$

where $\tau^{2}$ is the mass radius of gyration 


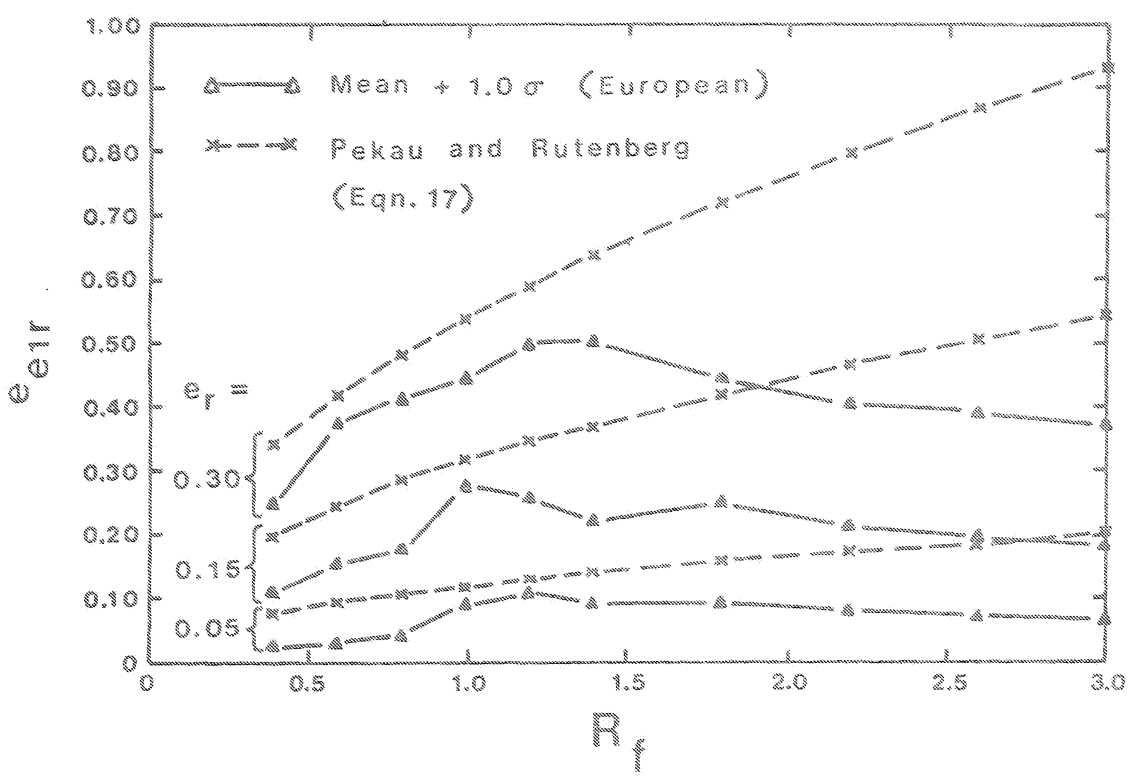

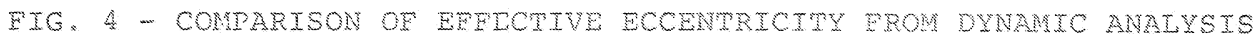
WTH THE RECOMENDATMONS OF PEKAU AND RUTEWBERG (EGN, 17)

about CS. Nowing that $R_{F}=\left(\mathrm{R}_{\theta} / \mathrm{T}^{2} \mathrm{~K}_{\mathrm{y}}\right)^{1 / 2}$, and employing eqne. (14) and (15), gives

$$
\Omega_{0}=R_{f} \frac{\tau}{\rho}=R_{E}\left(1 \text { wir } 2 e_{Y}^{2}\right)^{-i / 2}
$$

Hence eqn. (13) can be witten

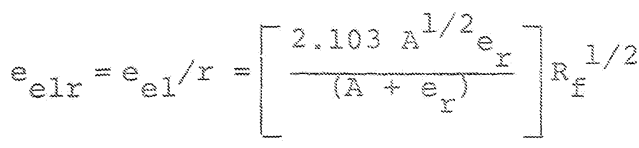

where

$$
A=\left(0.5 \cdots e_{x}^{2}\right)^{1 / 2}
$$

The inclusuon of the factor $\mathrm{R}^{1 / 2}$ in eqn. (17) is intenced to improve the coxrelation with dynamic results at the extreme ends of the range of Exequency ratiol6 (0.4< $\mathrm{R}_{\mathrm{k}}<3.0$ in Fo. H). Whe presented results show, however, what the improvement 3 onk applicable for $k_{4}<1.2$. since for higher values of $R_{p}$ the efwective eccentricity is reduced comoüred with peak values and hence the dynamic results diverge Erom the proposed design formula consequenty yieldirg an ovex-conservative al lowance for torsional esfects. Comparing the provisson of eqn. (17) For RE $=1.2$ with the dynamic results for $\mathrm{R}_{\mathrm{f}}>1.2$ in Fig. 4 indicates that such a provision gives conservative results throughout the range of structural eccentricity $e_{x}$ shown. Herce it is recommended that the tactor $R_{f} l / 2$ in eqn. (17) be included, if at all. For $R_{f}<1.2$, where it produces an improved correlation with dynamic results. It conservative in most cases, however, wo Lanore this factor a wogether (equivalent to taking $\left.\mathrm{R}_{E}=1.0\right)$ leading to a simplified design approach based on the magnitude of the structural eccentricity alone.
219. 5 shows the variation of erfectw tye eccenturity with ex for selected values of $R_{\text {f }}$ in the range $0.6 \mathrm{w}$. 7 . The spread of rewuts reduces as the frequency ratio increases, hence it is recommended that any proposed design provisions should be based on the "mean +1 . oo" dyramic results, correlating with existing code provksums which have been based largeiy on whe results of paramertic studies employing keansed mear $+1.00^{*}$ desion soectra to represent the earthouake 1 nout $5,8,27$. The perk response effects ocour for Re in the

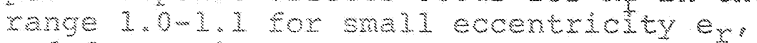
and for $\mathrm{k}$ in the mange $1.2 \mathrm{~m}$. 4 rom buld ings with noderate or large structural eccentricity (Fig. 5) . $\mathrm{For}_{\mathrm{F}}=0.6$ and $e_{y}>0.20$, very arge responses ocour (Fiq. 5 (a) . Whis coxditon should semsibly be avotded in design, however, snce unaceeptw ably large torsiona displacements anjse in builings with large structural eccentw

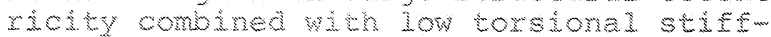
ness. me zi certro results lie below the mean European $x$ esutes for $\mathrm{R}_{\mathrm{F}}=0.6$. but for $1.1<R_{F}<1.4$ and $e_{r}<0.20$ they 1 e cuse to the extreme Erropean results, thereby indiceming the imoortande of considering a number of earthguakes when atwempting to dertify consisent response trends.

Puxther comorison of dynamio results with the recommendations of Pekau and Rutembergib (eqn. (17)) is shom in Eig. 6 . Where it is conismed that the provision For $R_{p}=1.0$ ervelopes the "mean t 1.00" dymamic resurs over the full range of cocentricity ex and that over-conservative provisurg are obtaned by incluang the sactor $R_{E} / 2$ wher $R_{F}>1.0$.

since thexe 35 Httue consistercy in the value of wrequency ratio kr at which peak estective eccentricity occurs it is of interest to compute the envelope of dynamic resulss dobured over a range of 

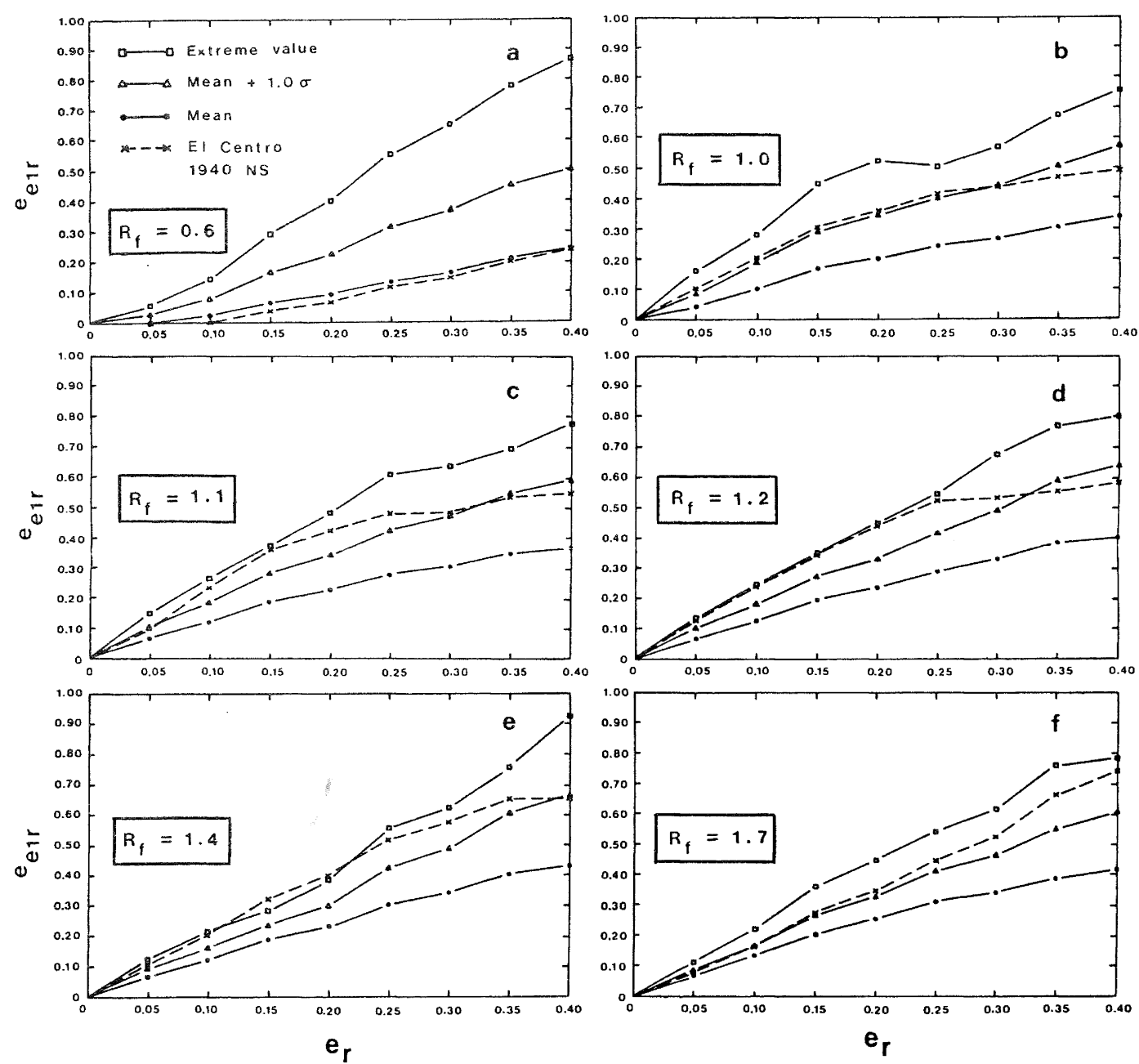

FIG. 5 - VARIATION OF EFFECTIVE ECCENTRICITY WITH $e_{r}$ AND $R_{f}$

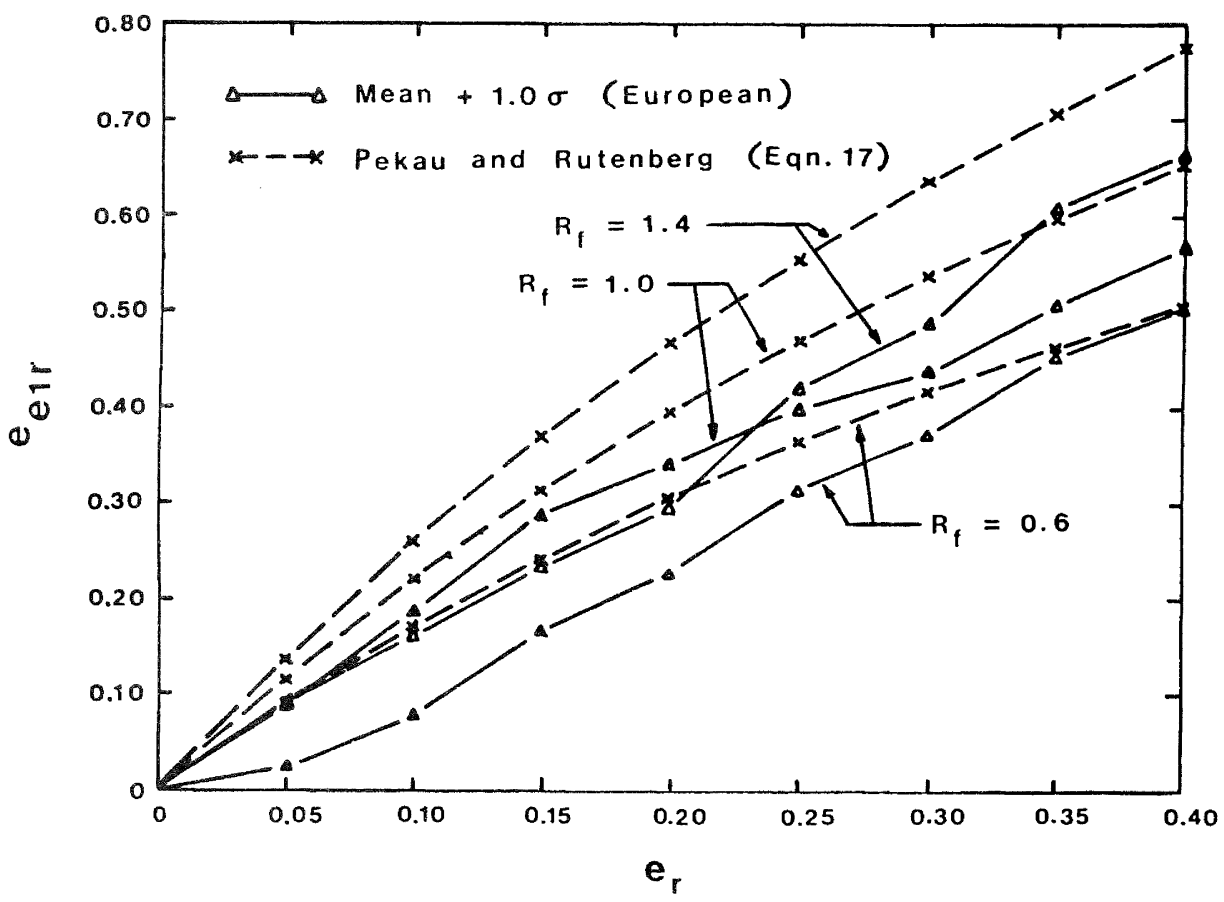

FIG. 6 - COMPARISON OF DYNAMIC RESULTS WITH THE PROVISIONS OF EQN. 17 
$R_{f}$, typically $0.6<R_{f}<2.0$. The response curves presented in Fig. 7 (a) have been derived on this basis, and show that the 'mean $+1.0 \sigma$ ' European results correlate closely with the El Centro response curve. The larger slope of the effective eccentricity curves for small values of structural eccentricity ratio $e_{r}$ is a reflection that the effect of modal coupling is more significant for this case, as may be observed in eqn. (17) in which the ratio $e_{e} 1 r / e_{r}$ decreases with increasing $e_{r}$. This slope is approximately 2.5-3.0 in the small eccentricity range, and has a value close to unity for large values of $e_{r}$. Based on the results of dynamic analysis employing idealised flat and flat-hyperbolic design spectra, Dempsey and Tsoll derived an approximate bi-linear relationship between the peak effective eccentricity and static eccentricity, namely

$$
\begin{array}{ll}
e_{e l r}=3 e_{r} & , e_{r} \leq 0.08 \\
e_{e l r}=0.172+0.85 e_{r}, & e_{r}>0.08
\end{array}
$$

as shown in Fig. $7(\mathrm{~b})$ in comparison with the 'mean $+1.0 \sigma^{\prime}$ ' European response envelope. The Dempsey and Tso provisions give conservative results for $e_{r}<0.10$, but underestimate the torsional coupling effect for buildings with moderate or large eccentricity. The magnitude of the underestimation increases with eccentricity, such that for $e_{r}=0.40$ the dynamic effective eccentricity exceeds the design provision of eqn.

(19b) by $40 \%$.

The Peakau and Rutenberg provision for $R_{f}=1.0$ is also shown in Fig. $7(b)$, and gives a better match with dynamic results than eqn. (19) while underestimating to a small extent the responses for moderate and
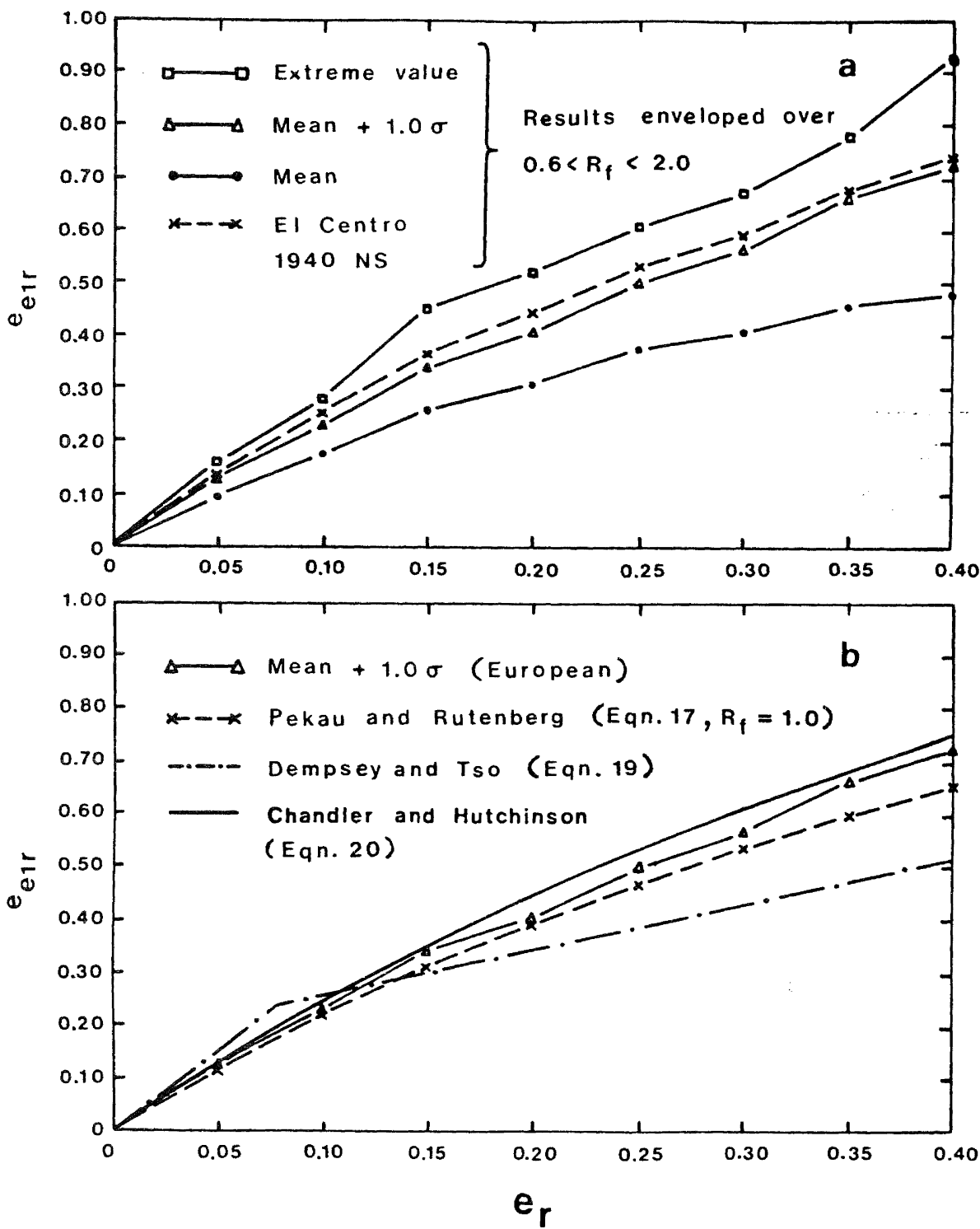

FIG. 7 - VARIATION WITH $e_{r}$ OF THE ENVELOPES OF EFFECTIVE ECCENTRICITY (a), AND COMPARISON WITH PROPOSED DESIGN PROVISIONS (b) 
large eccentricity $e_{x}$. The correlation would be improved by taking the case $R_{f}=$ 1.2 in eqn. (17), increasing the design provision by approximately $10 \%$. This confirms the earlier comments relating to Fig. 4. However, if it is required that the design recommendation for effective eccentricity should cater for the worst-case situation, then it is more sensible to incorporate this case in the design formula based on the eccentricity alone (a parameter more easily and reliably determined than the frequency ratio $R_{f}$ ). By this method the designer ensures a conservative allowance for torsional coupling effects whilst maintaining simplicity. The option may then be given for reducing the design effective eccentricity provision in cases where the modal coupling effect is less significant, based on the determination of $\mathrm{R}_{\mathrm{f}}$ by either empirical methods or a simplified dynamic analysis of the building to determine its lower frequencies and corresponding mode shapes.

Utilizing the above design approach, the authors have proposed a design expression based on effective eccentricityl3 in the form

$$
e_{e l r}=e_{r}\left(2.6-1.8 e_{r}\right)
$$

as shown by the solid curve in Fig. $7(\mathrm{~b})$. This provision conservatively envelopes the dynamic results based on the 'mean + $1.0 \sigma^{\prime}$ responses, and is straightforward to implement. The form of this design expression is similar to the recommendation of the
1976 version of the New Zealand code 23

(based on dynamic eccentricity), namely

$$
e_{d l r}=e_{r}\left(1.7-0.5 e_{r}\right)
$$

This provision was revised in $1984^{24}$ to read

$$
e_{\text {dlr }}=e_{r}
$$

An evaluation of current building code provisions for torsional effects is given in the following section.

\section{COMPARISON OF EARTHQUAKE RESPONSE WITH BUILDING CODE ESTIMATES}

The primary storey design torque as specified by the various provisions is expressed from eqn. (1) as

$\mathrm{T}_{\mathrm{bl}}=\mathrm{T}_{\mathrm{ebl}}+\mathrm{T}_{\mathrm{a}}=\alpha e \mathrm{~V}_{\mathrm{x} 0}+\beta \mathrm{Y} \mathrm{V}_{\mathrm{x} 0}$

where $\alpha, \beta$ are coefficients specified in Table 1 , and $\mathrm{Y}$ is the building plan dimension perpendicular to the applied earthquake loading (Fig. 1).

The supplementary eccentricity $e_{1}$ specified by Eurocode 8 (Table 1) is assigned the smaller of the two values computed from the following expressions

$\mathrm{e}_{1}=0.1(\mathrm{X}+\mathrm{Y})(10 \mathrm{e} / \mathrm{Y})^{1 / 2}, \leqq 0.1(\mathrm{X}+\mathrm{Y})$

$e_{1}=(1 / 2 e)\left\{p^{2}-e^{2}-q^{2}+\left[\left(p^{2}+e^{2}-q^{2}\right)^{2}+4 e^{2} q^{2}\right]^{\frac{1}{2}}\right\}$
TABLE 1 : COEFFICIENTS FOR PRIMARY DESIGN ECCENTRICITY

Building Codes

\begin{tabular}{|c|c|c|}
\hline ATC3 (U.S.A.) 20 & 1.0 & 0.5 \\
\hline Canada 21 & 1.5 & 0.10 \\
\hline $\operatorname{Mexico}^{22}$ & 1.5 & 0.10 \\
\hline New Zealand $(1976)^{23}$ & $1.7-0.5 e_{r}$ & 0.10 \\
\hline New Zealand $(1984)^{24}$ & $1.0 \quad r$ & 0.10 \\
\hline $\begin{array}{l}\text { Eurocode } 25 \\
\text { CEB }^{26}\end{array}$ & $1+e_{1.5}{ }_{1 r} / e_{r}$ & 0.05 \\
\hline
\end{tabular}

$\alpha$

B

where

$\mathrm{X}=$ the plan dimension of the building parallel to the direction of the applied earthquake forces (Fig. 1)

$\mathrm{p}^{2}=\left(\mathrm{X}^{2}+\mathrm{Y}^{2}\right) / 12$, and

$\mathrm{q}^{2}=$ the ratio of the torsional and translational stiffnesses the structure $\left(\mathrm{K}_{\theta} / \mathrm{K}_{\mathrm{v}}\right)$

Furthermore, $e_{1}$ is to be neglected when $\mathrm{q}^{2}>5\left(\mathrm{p}^{2}+\mathrm{e}^{2}\right)$.

Expressing the supplementary eccentricity ratio $e_{l r}\left(=e_{l} / r\right)$ in terms of $e_{r}$ and $\mathrm{R}_{\mathrm{f}}$ gives 12

$$
\mathrm{e}_{1 \mathrm{r}}=0.894\left(\mathrm{e}_{\mathrm{r}}\right)^{\frac{1}{2}}, \leqq 0.4
$$

or

$$
\begin{aligned}
e_{1 x}= & \left(0.5 / e_{r}\right)\left\{0.667-e_{r}^{2}-0.5 R_{f}^{2}+\right. \\
& {\left.\left[\left(0.667+e_{r}^{2}-0.5 R_{f}^{2}\right)^{2}+2 e_{f}^{2} R_{f}^{2}\right]^{\frac{1}{2}}\right\} }
\end{aligned}
$$

The lower of the two values furnished by eqns. (23a), (23b) is taken provided

$$
\mathrm{R}_{\mathrm{f}}^{2}<10\left(0.667+\mathrm{e}_{\mathrm{r}}^{2}\right)
$$

If eqn. (24) is not satisfied, then $\mathrm{e}_{1 r}=0$. Note from eqn. (23a) that $\mathrm{e}_{1 r}$ reaches its peak value 0.4 when $e_{r}=0.2$. Eurocode 8 specified that buildings with static eccentricity exceeding 10 per cent of the building plan dimension should be classified as 'irregular'. Buildings in this category should normally be analysed by a more exact approach taking into account increased torsional vibrations and based on a response spectrum modal analysis or a direct three-dimensional dynamic analysis. The 1984 version of the New Zealand code 24 makes a similar recommendation, which is used to justify the dropping of the parabolic dynamic eccentricity formula of the 1976 version 23 , eqn. (2la). This argument contradicts dynamic results, which indicate that torsional coupling effects are reduced in buildings with large structural eccentricity ${ }^{9}, 15,16$, and such buildings are therefore suited to simplified design for torsional effects using an empirical procedure such as that given in eqn. (22). For torsionally uncoupled 
systems, the coefficient $\alpha$ can be taken as 1.0 as in the 1984 New Zealand code (Table 1 and eqn. (2lb)). Hence the effects of modal coupling need to be accounted for in particular for buildings with small or moderate eccentricity, leading to a design expression in the form of eqn. (20).

A more convincing argument put forward for the adoption of eqn. (2lb) in the 1984 New Zealand code is that inelastic building responses under severe ground shaking tend to reduce the influence of torsional coupling 31 , and hence results based on linear elastic analyses may be over-conservative. This effect is also cited by the writers of the ATC 3 code20, which specifies a similar design eccentricity provision to the 1984 New Zealand code (Table 1), except that the accidental eccentricity is taken as $0.05 \mathrm{Y}$ in the former case. Studies of the inelastic seismic response of asymmetric structures indicate that ductility demand can in such cases be controlled better when the strength of the edge members is not lower than predicted by linear analysis 32 . Furthermore, Tso and Bozorgnia 33 have shown that the elastic effective eccentricity curves proposed in a previous studyll (eqn. (19) and Fig. $7(\mathrm{~b})$ ) can provide a reasonable or relatively conservative estimate for inelastic effective eccentricity, and hence these curves can be used to estimate the edge displacement and element deformation of inelastic eccentric systems. Hence, although it is acknowledged that in a strong earthquake it is likely that many of the resisting elements of a building will be excited into the inelastic range, elastic analyses such as those presented in this study give valuable information to ensure that an adequate allowance is made for the worst-case effects of torsional coupling in eccentric buildings. Inelastic response of asymmetric structures is a complex problem which has received much less attention than the elastic case; the nature and magnitude of changes (if any) to the existing torsional design provisions of building codes to account for inelastic effects need therefore to be studied further, to assess the significance for both conceptual and detailed design of asymmetric buildings.

The design eccentricity given by existing codes can be written from eqn. (22) as

$$
e_{b l}=T_{b l} / V_{x 0}=\alpha e+\beta Y
$$

and for the model shown in Fig. 2, eqn. may be written

$$
\mathrm{T}_{\mathrm{bl}}=\alpha \mathrm{e}_{\mathrm{r}}\left(\mathrm{rV} \mathrm{x} 0_{\mathrm{X}}\right)+2 \beta\left(\mathrm{r} \mathrm{V}_{\mathrm{x} 0}\right)
$$

From the first term of eqn. (26), the dynamic eccentricity ratio is defined as

$$
e_{\mathrm{dlr}}=\mathrm{e}_{\mathrm{dl}} / \mathrm{r}=\mathrm{R}_{\mathrm{ebl}} / \mathrm{r} \mathrm{v}_{\mathrm{x} 0}=\alpha \mathrm{e}_{\mathrm{r}}
$$

The dynamic eccentricity ratio defined in eqn. (27) represents the code allowance for torsional coupling, in terms of the amplification of static eccentricity required to give the design torsional moment $\mathrm{T}_{\mathrm{ebl}}$
Previous studies ${ }^{9}, 15$ comparing the code provisions with results of dynamic analyses utilising both idealised response spectra and time history analyses have shown that for particular ranges of the controlling parameters $e_{r}$ and $R_{f}$ typical of many real buildings, the building codes underestimate both the dynamic torque and to a lesser extent the edge displacement response.

The effective eccentricity concept provides an alternative approach to the primary design eccentricitv expression, viz

$$
e_{b l}=e_{e l}+e_{a}
$$

where $e_{a}$ is the component of design eccentricity which accounts for accidental torsional effects. The corresponding accidental torque $\mathrm{T}_{\mathrm{a}}=\mathrm{e}_{\mathrm{a}} \mathrm{V}_{\mathrm{x} 0}$ and hence, by analogy with the second term of eqn. (26)

$$
\left.e_{a r}=e_{a} / r=2 \beta \quad \text { (see Table } 1\right)
$$

The primary design eccentricity expressions of the codes listed in Table 1 are compared in Fig. 8, where the design and static eccentricities $e_{b l}$ and $e$ have been normalised to $s$, the 'characteristic' or maximum floor plan dimension taken perpendicular to the earthquake direction $(s=Y$ in Fig. 1, and $s=2 x$ in Fig. 2). In this form, the provisions are applicable to general floor plan shapes. The Eurocode 8 provision shown in Fig. 8 corresponds to the case $Y / X=1, R_{f}=1.0$.

Comparison is made in Fig. 8 with the design eccentricity based on eqn. (28), in which the effective eccentricity e el is taken from the 'mean $+1.0 \sigma$ ' dynamic response (enveloped with respect to $R_{f}$, as in Fig. 7 (b), and $e_{a}$ is taken as $0.05 \mathrm{~s}$. It is noted that although based on a different concept (that of dynamic eccentricity), the code provisions nevertheless provide a valid comparison with the effective eccentricity curve since both recommendations stem from the same equivalent static torque procedure, namely the product of the design storey shear $V_{x 0}$ with the specified dynamic or effective eccentricity, $e_{\mathrm{d} l}$ or eel respectively (eqns. (27), (6)).

The ATC3 and CEB codes are both severely non-conservative over the full range of eccentricity, and the New Zealand (1984) code is shown to be inadequate for $e_{s}>0.04$. This results from the inadequate provision of these codes for amplification of eccentricity due to modal coupling, with factors of 1.0 (ATC3, New Zealand) and 1.5 (CEB) respectively. These values should be compared with the factor of 2.6 at small eccentricities in the author's recommendation (Ref. 13), which can be written in terms of the plan dimension $s$ as

$$
e_{e l s}=e_{s}\left(2.6-3.6 e_{s}\right)
$$

By increasing the accidental eccentricity component $e_{a}$ from 0.05 to $0.10 \mathrm{~s}$, as in the Canadian, Mexican and New Zealand codes (Fig. 8), the percentage increase in design eccentricity is more significant for build- 


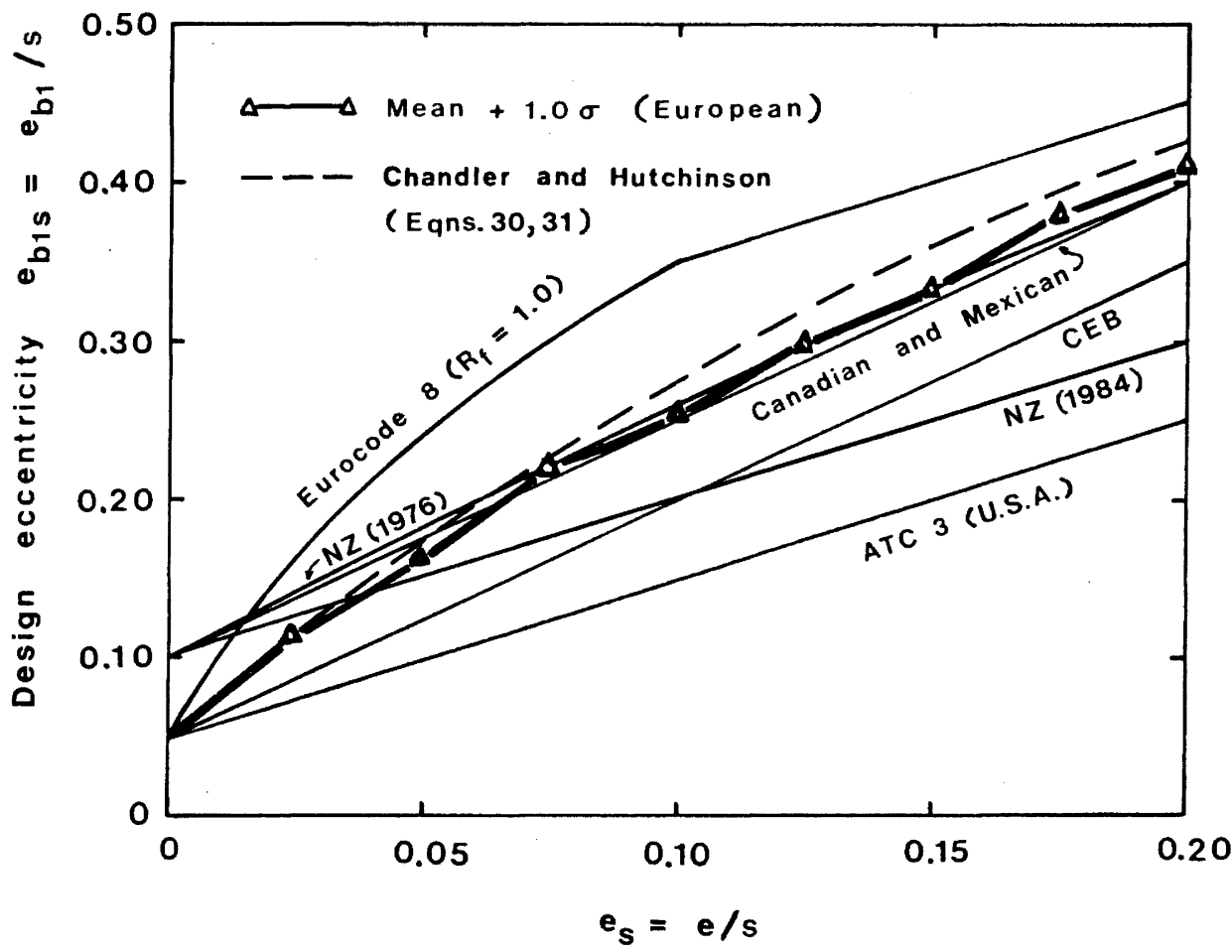

FIG. 8 - CODIFIED DESIGN ECCENTRICITY, COMPARED WITH DYNAMIC RESULTS BASED ON CONCEPT OF EFFECTIVE ECCENTRICITY

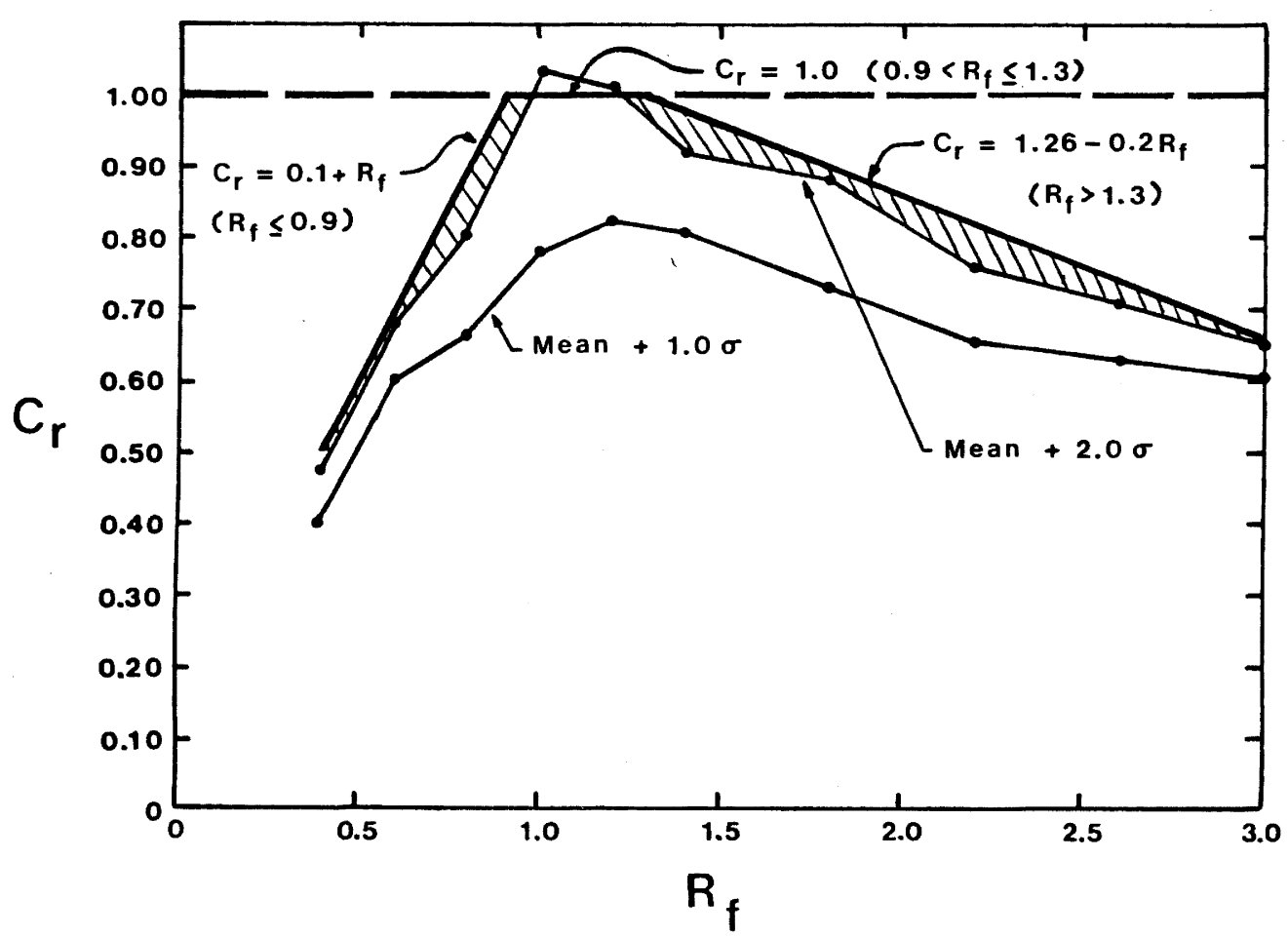

FIG. 9 - REDUCTION COEFFICIENT FOR THE PRIMARY DESIGN EFFECTIVE ECCENTRICITY 
ings with small eccentricity than for buildings with large eccentricity. This fits the observation that torsional coupling is more important for buildings with small eccentricity, and furthermore it is for these cases in particular that the majority of current code provisions underestimate torsional effects and thus need a compensating increase. Hence, the design provision of the Canadian and Mexican codes envelopes at small eccentricities the effective eccentricity curve based on 'mean $+1.0 \sigma$ ' results, and is a good match at moderate to large eccentricities 10.05 $\left.<e_{s}<0.20\right)$. The curve corresponding to the former New Zealand code provision (1976) is shown to provide an even better match with dynamic results for $e_{s}>0.08$.

Taking into account therefore the contributory factors mentioned earlier, the use of $0.10 \mathrm{~s}$ as the accidental eccentricity instead of $0.05 \mathrm{~s}$ does not appear to be excessive. It should also be remembered that implicit in the presentation of the dynamic results in $\mathrm{Fig} .8$ is that the accidental eccentricity is taken as $0.05 \mathrm{~s}$, and the effect of an increase to $0.10 \mathrm{~s}$ as in the Canadian, Mexican and New Zealand codes is eroded for buildings with eccentricity $0.05<e_{s}<0.20$ by the additional torsional effect caused by modal coupling.

In Fig. 8, the Eurocode 8 provision is found to be over-conservative over the full range of $e_{s}$, and furthermore its complexity compared with other codes makes the recommendations of the Canadian and Mexican codes in particular more attractive to designers. As mentioned earlier, the match with dynamic results can be improved by adopting eqn. (30) for the effective eccentricity provision, the accidental eccentricity being assigned a value $>0.05 \mathrm{~s}$ as deemed appropriate. Further reseārch is needed to improve the reliability of estimates of accidental eccentricity, for which currently no definitive work exists.

\section{MODIFICATION OF DESIGN EFFECTIVE ECCENTRICITY}

As shown in Fig. 8, the recommendation of eqn. (30) provides a conservative estimate of the worst-case dynamic response for all realistic values of $e_{s}$ and $R_{f}$. Noting the shape of the dynamic curves presented in Fig. 4, however, it is clear that the recommendations in their present form will be over-conservative for $R_{f}<0.9$ and to a lesser extent for $R_{f}>1.3$. It is therefore proposed that in these ranges the design effective eccentricity should be reduced using a reduction coefficient $C_{r}$ (< 1.0$)$ as shown in Fig. 9. The design envelope is fitted to the results obtained by proportioning the actual 'mean +2.00 ' dynamic responses (i.e. with only $2.3 \%$ probability of exceedance) to the design effective eccentricity provisions of eqn. (30), for a range of eccentricities $e_{s}$. Thus, implementing the reductions in effective eccentricity for $R_{f}<0.9$ or $R_{f}>1.3$ as shown in Fig. 9 ensures practically the same degree of confidence in the conservatism of the resultant design provision in these ranges as that which pertains in the range $0.9<R_{f}<1.3$, where there is no recommended reduction.

\section{SUMMARY OF RECOMMENDED DESIGN PROCEDURES}

1. The first-stage design eccentricity for structural members on the flexible side of the building (to the right of $\mathrm{CS}$ in Fig. 1) should take the form

$e_{b l s}=e_{e l s}+e_{a s}$

2. It is recommended that $e_{a s}$ be taken as 0.05 (5\% of the building plan dimension perpendicular to the incident earthquake direction) as incorporated in the dynamic results shown in Fig. 8.

3. The design effective eccentricity ratio e els in eqn. (31) is obtained from eqn. (30), and yields a conservative estimate of member displacement response for all frequency ratios $R_{f}$, based on mean plus one standard deviation dynamic results from a number of strong-motion earthquake records.

4. In cases where the value of $R_{f}$ has been evaluated to acceptable accuracy by empirical or dynamic analysis of the structure in uncoupled form $(e=$ $0)$, the first-stage design effective eccentricity eels can be modified at the designer's discretion using a reduction coefficient $C_{r}(<1.0)$, such that over the range of $R_{f}$ which is of interest for real buildings

$$
\left.\begin{array}{rl}
\mathrm{R}_{f} & \leq 0.9, \mathrm{C}_{r}=0.1+\mathrm{R}_{\mathrm{f}} \\
0.9<\mathrm{R}_{f} & \leq 1.3, \mathrm{C}_{\mathrm{r}}=1.0 \\
\mathrm{R}_{f} & >1.3, \mathrm{C}_{\mathrm{r}}=1.26-0.2 \mathrm{R}_{f}
\end{array}\right)
$$

Note that the reduction coefficient does not apply to the design accidental eccentricity $e_{\text {as }}$ which has a fixed value.

5. Where uncertainty exists in the calculated value of $R_{f}$, for example due to the simplified structural modelling often employed in dynamic analysis affecting the accuracy of the natural frequency calculations ${ }^{\text {, }}$, the reduction coefficient $\mathrm{C}_{r}$ should be taken as the largest value obtained over a range of $R_{f}$ around the calculated value. The size of the range considered will depend on the confidence placed in the natural frequency calculations.

6. The design lateral edge displacement of structural members at the furtherest distance from CS (the 'flexible edge' in Fig. 1) is calculated from the combined effects of the design storey shear $V_{x o}$ obtained using the equivalent static methods stipulated in the building codes, and the design storey torque given by $e_{b l} \mathrm{~V}_{\mathrm{xo}}$.

7. The design lateral displacement of other members on the flexible side of CS is calculated using the edge displacement obtained in stage 6 above, reduced in proportion to the distance of the member in question from CS, 
measured perpendicular to the direction of the earthquake input. This procedure has been found to yield conservative results for non-edge members 11,16 .

\section{CONCLUSIONS}

Design procedures for torsionally coupled buildings have been presented, based on earthquake response analysis of a monosymmetric single storey building model. These design recommendations differ in several important respects from the current torsional provisions stipulated in the major building codes.

All the current code provisions are based on a dynamic eccentricity procedure matching, by means of a specified design torque, the torsional moments induced in asymmetric structures when subjected to earthquake ground motion. The component of design torque which accounts for torsional coupling consists of an equivalent static value defined as the product of the design lateral shear force and the designated dynamic eccentricity. The latter quantity is assumed by most codes to be a simple linear function of the structural eccentricity. This approach has been shown to be over-simplistic and may seriously underestimate the edge displacement response over certain ranges of the parameters $e_{\mathbf{S}}$ and $R_{f}$ typical of most real buildings. A more logical approach based on the effective eccentricity concept has been used to match the maximum dynamic edge displacement of the structure, and hence this includes the combined effect of the coupled translational and torsional response components.

The derived effective eccentricity expressions provide a better approximation to the dynamic response over the relevant ranges of $e_{s}$ and $R_{f}$. This first-stage approximation is dependent on the value of the structural eccentricity only. The design effective eccentricity has been specified in normalised form as a ratio of the 'characteristic' or maximum plan dimension of the building perpendicular to the earthquake direction, and is therefore not restricted to particular floor plan shapes.

The parameter $R_{f}$ has been shown to influence significantly the magnitude of the coupled lateral-torsional response of asymmetric buildings. of all the current codes, only Eurocode 825 makes any allowance in its torsional design provision for the relative stiffness of the building in torsion and translation, a quantity related to $R_{f}$. This paper proposes that the firststage design effective eccentricity be employed to give a conservative estimate of the worst-case response, with an allowance that this value be reduced as appropriate in a second-stage procedure based on the value of $R_{f}$ as calculated for the design structure. This approach enables more flexibility in design and provides incentive for the designer to compute, on the basis of a simplified computer model of the proposed structure, the value of the uncoupled frequency ratio. In many cases this will enable a significant reduction in the design torque, thereby eliminating over-conservatism. Alternatively, design modifications might be implemented at an early stage in order to ensure negligible modal coupling effects by adjusting the value of $R_{f}$ away from the critical ranges.

\section{REFERENCES}

1. FOUTCH, D.A. - The vibrational characteristics of a twelve-storey steel frame building. Earthquake Engineering and Structural Dynamics, Vol.6, No.3, pp.265$294,1978$.

2. ESTEVA, L. et al - Lessons from some earthquakes in Latin America. Proceedings of the 4 th World Conference on Earthquake Engineering, Santiago, Chile, Vol. 3, Part J2, pp. 58-73, 1969.

3. CHANDLER, A.M. - Building damage in Mexico City earthquake. Nature, Vol. 320, No. 6062, pp. 497-501, 1986.

4. ROSENBLUETH, E. and MELI, R. - The 1985 earthquake: causes and effects in Mexico City. Concrete International, Vol. 8, No. 5, pp. 23-34, 1986.

5. ELMS, D.G. - Seismic torsional effects on buildings. Bulletin of the New Zealand National Society for Earthquake Engineering, Vol. 9, No. 1, pp. 79-83, 1986.

6. KAN, C.I. and CHOPRA, A.K. - Effects of torsional coupling on earthquake forces in buildings. Journal of the Structural Division, ASCE, Vol. 103, pp. 805-819, 1977.

7. DEMPSEY, K.M. and IRVINE, H.M. Envelopes of maximum response for a partially symmetric single-storey building model. Earthquake Engineering and Structural Dynamics, Vol. 7, pp. 161-180, 1979.

8. TSO, W.K. and DEMPSEY, K.M. - Seismic torsional provisions for dynamic eccentricity. Earthquake Engineering and Structural Dynamics, Vol.8, pp. 275-289, 1980.

9. TSICNIAS, T.G. and HUTCHINSON, G.L. Evaluation of code requirements for the earthquake resistant design of torsionally coupled buildings. Proceedings of the Institution of Civil Engineers, London, Vol. 71, Part 2, pp. 821-843, 1981.

10. TSCNIAS, T.G. and HUTCHINSON, G.L. Evaluation of code torsional provisions for earthquake resistant design of single storey buildings with two eccentricity components. Proceedings of the Institution of Civil Engineers, London, Vol. 73, Part 2, pp. 455-464, June 1982 .

11. DEMPSEY, K.M. and TSO, W.K. - An alternative path to seismic torsional provisions. Soil Dynamics and Earthquake Engineering, Vol. 1, No. 1, pp. 3-10, 1982

12. CHANDLER, A.M. - Coupled torsional response of single-storey building models 
to earthquake loading. Ph.D. thesis, University of London, 1985.

13. CHANDLER, A.M. and HUTCHINSON, G.L., Seismic design eccentricity for torsionally coupled buildings. Proceedings of the 8 th European Conference on Earthquake Engineering, Lisbon, Vol. 3, Part 6.7, pp. 33-40, 1986 .

14. CHANDLER, A.M. and HUTCHINSON, G.L. Torsional coupling effects in the earthquake response of asymmetric buildings. Engineering structures, Vol. 8, No. 4, pp. 222-236, 1986.

15. CHANDLER, A.M. and HUTCHINSON, G.L. Evaluation of code torsional provisions by a time history approach. Earthquake Engineering and Structural Dynamics, Vol. 15, pp. 491-516, 1987.

16. PEKAU, O.A. and RUTENBERG, A. Evaluation of the torsional provisions in the 1985 NBCC. Proceedings of the 5 th Canadian Conference on Earthquake Engineering, Ottawa, Part 6, pp. 739-746, 1987.

17. CHANDLER, A.M. and HUTCHINSON, G.L. Code design provisions for torsionally coupled buildings on elastic foundation. Earthquake Engineering and Structural Dynamics, Vol. 15, pp. 517-536, 1987.

18. KAN, C.L. and CHOPRA, A.K. - Elastic earthquake analysis of torsionally coupled multi-storey buildings. Earthquake Engineering and Structural Dynamics, Vol. 5, No. 4, pp. 395-412, 1977.

19. GLUCK, J., REINHORN, A. and RUTENBERG, A. - Dynamic torsional coupling in tall building structures. Proceedings of the Institution of Civil Engineers, Vol. 67, Part 2, pp. 411-424, 1979.

20. APPLIED TECHNOLOGY COUNCIL - Tentative provisions for the development of seismic regulations for buildings. Structural Engineers' Association of California, ATC306, U.S. National Bureau of Standards, Washington, D.C., 1984 .

21. NATIONAL BUILDING CODE OF CANADA Effects of Earthquakes. Associate Committee on the National Building Code, National Research Council of Canada, Subsection 4.1.9.1, Clauses 22,23, Ottawa, Ontario, 1985.

22. NATIONAL UNIVERSITY OF MEXICO - Design Manual for earthquake, according to the construction regulations for the Federal District of Mexico. No. 406, Chapter 37, Art. 240 (VII), 1977.

23. NEW ZEALAND STANDARD. - Code of practice for general construction design and design loadings for buildings. NZS 4203: 1976, Part 3, (Earthquake Provisions). Sections 3.4.7.2/3, Standards Association of New Zealand, Wellington, 1976.

24. NEW ZEALAND STANDARD. - NZS 4203:1984 (other details as Ref. 23).
25. EUROCODE NO. 8 - Common Unified rules for structures in seismic regions. Commission of the European Communities (draft), 1984

26. COMITÉ EURO-INTERNATIONAL DU BÉTON (CEB) - Seismic design of concrete structures, Gower Technical Press, U.K., 1987.

27. MULLER, F.P. and KEINTZEL, E. Approximate analysis of torsional effects in the new German seismic code DIN 4149 . Proceedings of the 6 th European Conference on Earthquake Engineering, Dubrovnik, Yugoslavia, Vol. 2, pp. 101-108, 1978.

28. RUTENBERG, A. and HEIDEBRECHT, A.C. Rotational ground motion and seismic codes. Canadian Journal of Civil Engineering, Vol. 12, pp. 805-820, 1985.

29. HALL, J.F. - An FFT algorithm for structural dynamics. Earthquake Engineering and Structural Dynamics, Vol. 10, No. 6, pp. 797-811, 1982 .

30. HART, G.C., DIJULIO, R.M. and LEW, M. - Torsional response of high-rise buildings. Journal of the Structural Division, ASCE Vol. 101, pp. 397-416, 1975.

31. KAN, C.L. and CHOPRA, A.K. - Torsional coupling and earthquake response of simple elastic and inelastic systems. Journal of the Structural Division, ASCE, Vol. 107, pp. 1569-1588, 1981 .

32. SHOET, G. - Ductility demand in asymmetric structures. Master's thesis, Technion-Israel Institute of Technology, Haifa.

33. TSO, W.K. and BOZORGNIA, Y. - Effective eccentricity for inelastic seismic response of buildings. Earthquake Engineering and Structural Dynamics, Vol. 14, pp. 413-427, 1986 . 